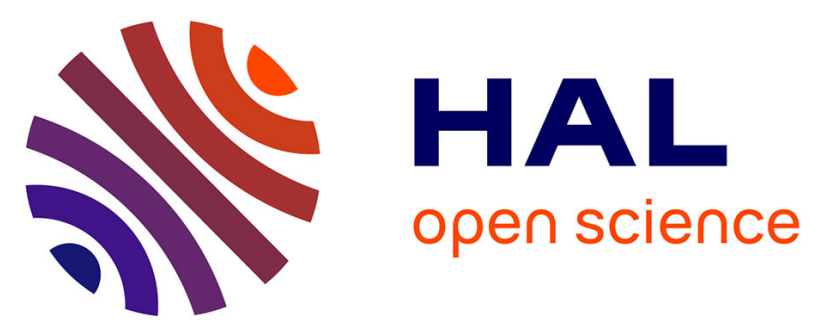

\title{
The effect of optokinetic and galvanic vestibular stimulations in reducing post-stroke postural asymmetry
}

Isabelle Bonan, Emilie Leblong, Stéphanie Leplaideur, B. Laviolle, Sophie Tasseel Tonche, A. P. Yelnik

\section{- To cite this version:}

Isabelle Bonan, Emilie Leblong, Stéphanie Leplaideur, B. Laviolle, Sophie Tasseel Tonche, et al.. The effect of optokinetic and galvanic vestibular stimulations in reducing post-stroke postural asymmetry. Clinical Neurophysiology, 2016, 127 (1), pp.842-847. 10.1016/j.clinph.2015.03.026 . hal-01158657

HAL Id: hal-01158657

https://hal-univ-rennes1.archives-ouvertes.fr/hal-01158657

Submitted on 12 Nov 2015

HAL is a multi-disciplinary open access archive for the deposit and dissemination of scientific research documents, whether they are published or not. The documents may come from teaching and research institutions in France or abroad, or from public or private research centers.
L'archive ouverte pluridisciplinaire HAL, est destinée au dépôt et à la diffusion de documents scientifiques de niveau recherche, publiés ou non, émanant des établissements d'enseignement et de recherche français ou étrangers, des laboratoires publics ou privés. 
The effect of optokinetic and galvanic vestibular stimulations in reducing post-stroke postural asymmetry

BONAN IV ${ }^{\mathrm{a}}$, LEBLONG E ${ }^{\mathrm{a}}$, LEPLAIDEUR $^{\mathrm{a}}{ }^{\mathrm{a}}$ LAVIOLLE $\mathrm{B}^{\mathrm{b}}$,

TASSEL TONCHE $\mathrm{S}^{\mathrm{c}, \mathrm{d}}$, YELNIK AP

aPhysical Medicine and Rehabilitation Department, University Hospital, Faculty of Medicine, University of Rennes 1, - 2, rue Henri Le Guilloux 35033 RENNES Cedex 9, France;

${ }^{\mathrm{b}}$ Clinical pharmacology department University Hospital, Faculty of Medicine, University of Rennes 1, Hôpital Pontchaillou -2, rue Henri Le Guilloux 35033 RENNES Cedex 9 ${ }^{\mathrm{C}}$ PRM Department GH Saint Louis Lariboisière F Widal AP-HP, Université Paris Diderot, 200 rue du Fbg St Denis 75010 Paris, France

dPhysical Medicine and Rehabilitation Department, University Hospital, Faculty of Medicine, University of Amiens, avenue René Laënnec - SALOUEL 80054 Amiens Cedex 1, France

\section{Corresponding author:}

Isabelle Bonan

Physical Medicine and Rehabilitation Department

Centre Hospitalier Universitaire

2 rue Henri le Guilloux 35000 Rennes, France.

Tel.: +33299284218

Fax: +33299284183

E-mail: Isabelle.bonan@chu-rennes.fr 


\section{HIGHLIGHTS}

1- Both optokinetic and galvanic vestibular stimulations modulate the position of the Center of Pressure $(\mathrm{CP})$ in people with hemiparesis.

2- The correction action of sensory stimulation for postural asymmetry is more effective in RHL suggesting a high level cortical effect on body's representation of space.

3- The effect of both sensory stimulations are significantly correlated suggesting a common or at least overlapping central mechanism in relation to postural control. 


\section{Abstract}

Objective: To investigate the postural effect of 2 types of sensory stimulation in patients with a left hemispheric lesion (LHL) or right hemispheric lesion (RHL) compared with controls.

Methods: 35 patients (18 LHL, 17 RHL) and 27 controls (Mean age 54.1 years), with a mean delay post-stroke of 3.0 months were enrolled. Subjects stood on a force platform and were stimulated on the left and right side by optokinetic (Okn) and galvanic vestibular (Gv) stimulation. Lateral displacement following stimulation towards the right and left directions was calculated as the mean position of the centre of pressure $(\mathrm{CP})$ during the stimulation period minus the mean position at rest.

Results: Postural asymmetry was reduced in LHL and RHL patients. CP displacement was higher in cases of left-sided stimulation in the RHL group compared with control subjects and LHL patients (respectively 2.8 and 2.4 times higher, group effect, $\mathrm{p}<0.001$, group $\mathrm{x}$ direction of stimulation interaction, $\mathrm{p}=0.007$ ). The magnitude of displacement under Okn significantly correlated with $\mathrm{Gv}$ in all cases (rho $=0.635, \mathrm{P}<0.001$ ).

Conclusions: Both GV and Okn stimulations can modulate hemiparetic's CP and their postural effects are correlated.

Significance: Results support a high level cortical postural effect of sensory stimulation on supramodal spatial network.

Keywords: Postural control, sensory stimulation, rehabilitation, stroke. 


\section{INTRODUCTION}

Improving balance after stroke is of crucial importance because its improvement is strongly correlated to higher patient autonomy and improved quality of life (QoL). The characteristics of postural disturbances following stroke, as observed on a force platform, are of increased sway and a lateral displacement of the centre of pressure (CP) toward the non-paretic limb (Pérennou et al 1997, Rode et al 1998). The lateral displacement of the centre of pressure toward the lesion side is more important in patients with right hemispheric lesion (RHL) and this is thought to partly explain the predominance of postural imbalance in left hemiparetic patients. The excessive ipsilesional postural bias observed in RHL patients is probably due to spatial cognitive impairment leading to a distortion of the internal representation of body in space (Rode et al 1998). This assumption comes from the notion that the right hemisphere is responsible for spatial cognition (Pérennou et al 2008). A right-sided cerebral lesion may lead to pronounced disruption in the processing of spatial information and could impair the internal representation of the body in space and consequently postural orientation (Rode et al 1997, Pérennou et al 2001). The relationship between this postural bias observed in stroke patients and the disturbed perception of verticality has been previously discussed (Bonan et al 2006, Bonan et al 2007, Pérennou et al 1998, Pérennou et al 2008, Yelnik et al 2002), with patients with a hemispheric stroke aligning their erect posture with an erroneous reference of verticality, tilted to the side opposite the lesion (Pérennou et al 2014).

This postural bias can be reduced by sensory manipulations (Rode et al 1998, Perennou et al 2001, Tilikete et al 2001). Improvements in postural bias have been achieved with vestibular caloric stimulation (Rode et al 1998), proprioceptive transcutaneous electrical nerve stimulation (TENS) (Pérennou et al 2001) and visual prismatic adaptation (Tilikete et al 2001). However, the mechanism underlying such postural effects is not yet fully understood 
but is likely to be explained by a high level effect on body and space representation, rather than by a sensorimotor effect. It is thought that sensory stimulations activate preserved structures involved in the body's representation in space. This assumption comes from a variety of theories. Firstly, the postural effect predominates in patients with right hemispheric lesion (RHL), as compared to patients with left hemispheric lesion (LHL) (Pérennou et al 1997, Rode 1998 et al). This predominance is likely to be related to the spatial role of the right hemisphere. The right hemisphere is crucial for generating internal maps used for perception and pre-motor processing of spatial information. Secondly, sensory stimulation reduces postural imbalance, as well as numerous symptoms related to spatial cognition, such as visuospatial impairment in all its manifestations (sensory impairment as well as representative impairment or motor impairment).

We investigated here the postural effect produced by 2 types of sensory stimulation: visual stimulation (optokinetic) and vestibular stimulation (galvanic) in 2 groups of hemiparetic patients (i.e. RHL and LHL), as well as a group of control subjects. Our hypothesis was that both methods of stimulation would be effective in reducing lateral postural bias, and that this effect would be more significant in the RHL group compared with LHL patients and control subjects due to its effect on the distortion of space, and, moreover, that the effect would be equal between the LHL patients and control subjects. We then investigated the relation between the the effect of the 2 stimulations to provide further insight into the neural mechanisms underlying the postural effect of these sensory stimulations. 


\section{METHODS}

\subsection{Participants}

This study was reviewed and approved by the Comité de Protection des Personnes, Ile de France IV (number 2007/28). Patients were included into the study if they had recently (i.e. $<6$ months previously) experienced their first and only cerebral hemispheric stroke, with various sequelae, including motor and balance impairments. Prior to participating in any study-specific procedures all patients and subjects provided written informed consent. Patients were required to be able to remain standing without assistance or any supporting devices for 60 seconds. Patients were not included if they were $>80$ years of age, had reduced alertness or a pre-stroke history of neurological disturbances, vertigo, vestibular dysfunction, amblyopia, or diplopia. Aphasic patients were excluded if they were unable to fully understand the study procedure. A complete neurological examination was then carried out, including assessment of motor impairment using the Motricity Index (Collin and Wade 1990), and functional independence using the Barthel Index (Mahoney and Barthel 1965). Balance, was evaluated using the Berg Balance Scale (Berg et al 1989), gait velocity using the 10 metre and the Timed Up and Go test (Podsiadlo and Richardson 1991). Visual Field was assessed at the bedside. A CT scan or MRI of the brain and brain stem was carried out for each patient, and patients were excluded if these investigations revealed any tumours or pathologies of the posterior fossa.

Thirty-five patients were included (Table 1), 17 of whom were right-lesion hemiplegics (RHL) and 18 were left-lesion hemiplegics (LHL). The stroke was haemorrhagic in 14 patients and ischaemic in 21 patients. The cerebral lesion was divided into 10 areas using the Talairach classification (Talairach and Turnoux, 1988), assessed by a neuro-radiologist and 
the presence or absence of a lesion of the parieto insular vestibular cortex (PIVC), an area known to be of crucial importance for the integration of multisensory information, was ascertained.

The control group comprised 27 healthy subjects (14 males, 13 females) whose mean age was $51.7 \pm 12.6$ years and were matched to the stroke patients by age. These subjects had no musculoskeletal, vestibular, visual or somatosensory impairments, and none were taking medications known to interfere with alertness or postural control.

\subsection{Procedure}

\subsubsection{Rest Session}

Subjects stood barefoot at rest on a force platform (Technoconcept ${ }^{\circledR}$ ) for a period of 50 seconds. Lateral displacement of the $\mathrm{CP}$ was recorded at rest and the mean position of the $\mathrm{CP}$ in the mediolateral axis was calculated as the mean displacement on the mediolateral axis during this 50 second rest recording period and termed $\mathrm{x} 0$.

\subsubsection{Optokinetic Sessions (Okn Sessions)}

After an initial 15 second period of standing at rest, patients were stimulated by circular Okn stimulation for 35 seconds on a field of $100^{\circ}$ of visual angle. The speed of rotation was 60 degrees per second with moving luminous dots oriented clockwise (i.e. right Okn stimulation) or counter-clockwise (i.e. left Okn stimulation) to induce mediolateral postural displacement. Patients were instructed to stare straight ahead at the stimulus pattern without attempting to follow the moving dots. Right and left visual stimulation were tested over separate sessions, with the patient receiving a rest period in which they were seated for at least 3 minutes. 


\subsubsection{Galvanic Sessions (Gv Sessions)}

After an initial 15 second period of standing at rest, subjects were stimulated by binaural $\mathrm{Gv}$ stimulation over 35 seconds. Binaural bipolar Gv vestibular stimulation was delivered at an intensity of $2 \mathrm{~mA}$ by $9 \mathrm{~cm}^{2}$ rectangular $\mathrm{Ag}-\mathrm{AgCl}$ pre-gelled disposable electrodes placed over each mastoid in a lit room with the patient's eyes open. The electrodes were secured with adhesive tape and an elastic bandage wrapped around the head. Gv stimulations were trapezoidal comprising a 3 second ascending ramp, followed by a 29 second plateau and a 3 second descending ramp. The cathode was placed on either the right or left mastoid process to induce mediolateral postural displacement. Two directions of Gv stimulation were tested over separate sessions: left displacement (left Gv stimulation) or a right (right Gv stimulation), being separated by a rest period of at least 3 minutes during which the patients were seated.

\subsection{Data Analysis}

Lateral displacement of the patients under Okn stimulation toward the right (R-Okn) and toward the left direction (L-Okn) was calculated as the mean position of the $\mathrm{CP}$ during the 5 to 30 second stimulation period, minus the mean position during the 1 to 12.5 second initial rest period. Similarly, displacement of the patients under Gv stimulation was calculated as the mean position of the $\mathrm{CP}$ during the 20 to 45 second stimulation period, minus the mean position during the 1 to 12.5 initial period of rest. These were termed R-Gv and L-Gv, respectively. 


\subsection{Statistics}

Statistical analysis was performed using SAS statistical software v 9.3 (SAS Institute, Cary, NC, USA).The characteristics of LHL and RHL were compared using the Mann Whitney test. A 3-way ANOVA was used to compare the displacement of the patients whilst undergoing stimulations. The 3 key factors were the group (i.e. controls, RHL, LHL), modality of the stimulation (i.e. Gv and Okn) and the direction of the stimulation (left or right). The group effect compared the 3 groups, all modalities of stimulation and directions being combined. The stimulation effect compared the Gv to the Okn method, with all groups and directions being combined. The direction effect compared left and right stimulation, with all groups and type of stimulations being combined. Three first order interactions (group $\mathrm{x}$ stimulation, group $\mathrm{x}$ direction and stimulation $\mathrm{x}$ direction) were also entered in the model. Spearman correlation coefficients between the magnitude of the displacement obtained under Okn and Gv were also assessed. For all analyses, a $\mathrm{p}$ value $<0.05$ was considered statistically significant. 


\section{RESULTS}

\subsection{Demographic and Balance Data}

Patient demographic and balance data are detailed in Table 1. There were 22 males and 13 females, presenting with 21 ischaemic lesions and 14 haemorrhagic lesions. No differences were found between LHL and RHL patients, except for the postural bias at rest (x0) that was higher in RHL than in LHL patients ( $\mathrm{p}=0.0477$ ). Ten patients (7 LHL, 3RHL) had a lesion involving the PIVC (parieto-vestibular-insular-Cortex). Visual field defect was observed in three patients (1 RHL and 2 LHL) and these patients were included in the analyses.

\subsection{Effect of Type and Direction of Stimulation}

Compared with the rest position, $\mathrm{CP}$ position during stimulation was displaced either left or right according to the direction of the stimulation in all 3 groups. Displacements during stimulation, expressed in absolute values, are shown in Table 2. ). No difference was found in the displacement under stimulation between patients with PIVC lesion and patients without PIVC lesion. The displacement under stimulation was not correlated to motricity $(\mathrm{p}=0.763$, rho $=-0.05)$ nor to delay since stroke $(\mathrm{p}=0.433$, rho $=0.114)$.

There was a significant group effect $(\mathrm{F}=7.52, \mathrm{p}<0.001)$, together with a significant group $\mathrm{x}$ direction interaction $(\mathrm{p}=0.007)$ showing that displacement was higher with respect to left stimulation only in RHL patients, compared with controls and LHL patients (Figure 1). In fact, left displacement was 2.8 times and 2.4 times higher in RHL compared with LHL and 
control subjects, respectively ( $\mathrm{p}<0.001$ for both), and right displacement did not differ between the 3 groups ( $\mathrm{p}=0.668$ ). Interestingly, left displacement in RHL (i.e. reducing the postural asymmetry of RHL) was 2.2 times higher than the right displacement (i.e. reducing the postural asymmetry of LHL) in LHL ( $<<0.0001)$. Moreover, the left and right displacements did not differ between LHL and control groups ( $\mathrm{p}=0.503)$.

There was also a significant stimulation effect $(\mathrm{F}=9.09, \mathrm{p}=0.003)$ showing that displacement was 1.6 times higher with Okn than with Gv stimulation.

Overall, when all groups were combined, the magnitude of displacement was positively correlated between Okn and Gy (rho=0.635, $\mathrm{p}<0.001)$. Subgroup analysis showed that this correlation was also evident in control subjects $(\mathrm{rho}=0.645, \mathrm{p}<0.001), \mathrm{LHL}(\mathrm{rho}=0.557$, $\mathrm{p}=0.001)$ and RHL $(\mathrm{rho}=0.638, \mathrm{p}=0.002)$. However, individual subject analysis indicated that some subjects responded to one or other method of stimulation, but not to both (Figure 2). Moreover the side of the responses to an oriented stimulus was not always the same for Gv and Okn stimulus (figure 2). 


\section{DISCUSSION}

As expected, our findings showed that the lateral position of the $\mathrm{CP}$ at rest was more marked in right-lesion patients than in those with left-sided lesions, which concurs with previous studies (Pérennou et al 1998, Rode et al 1998). This excessive ipsilesional postural bias after right stroke is thought to be due to body misorientation (Rode et al 1997, Pérennou et al 2001).

We found that postural asymmetry is reduced by sensory stimulation in RHL and LHL patients. However, the responses to sensory stimulation of LHL patients did not differ from those of the control group, and did not differ between left and right directions. Therefore, it would appear that the presence of a left cerebral lesion does not seem to influence the effect of sensory stimulation, since the effect is the same as for normal subjects. Yet, LHL sufferers do often have a spontaneous bias at rest, albeit smaller than that found in RHL patients. It could therefore be assumed that the ipsilesional bias observed in LHL is not related to high level postural disturbances, but could be mostly due to the biomechanical consequences of impaired motricity or somesthesie, or due to compensatory processes established to address imbalance (Genthon et al 2009). Despite being less effective than for RHL (i.e. being half as effective in LHL compared RHL), sensory stimulation could nevertheless correct the bias observed in LHL to force utilisation of the hemiparetic lower limb. However, the potential benefits for the correction of this bias in LHL should be discussed as it may actually represent a useful adaptation for hemiparetic patients thereby allowing them to cope with imbalance (Genthon et al 2009, Roerdink et al 2009).

As with other studies, we showed that the postural effect was nearly double for RHL patients compared to that for LHL, and compared to the responses of LHL and control subjects, the 
responses of RHL sufferers were much higher when the stimulation induced displacement towards the left direction (Rode et al 1998, Tilkete et al 2001). As the clinical characteristics of the 2 groups of patients did not differ significantly, these characteristics cannot be considered responsible for the increased responses in the RHL group. Therefore, localisation of the lesion in the right hemisphere seems to be responsible for the direction specific effect of sensory stimulation on postural disturbances. These results strongly suggest that the excessive postural effect of sensory stimulation in RHL patients results from changes that occur in the right hemisphere, probably in those centres responsible for spatial representation (Pérennou et al 1998, Rode et al 1998, Tilikete et al 2001). This postural effect might be a high level effect resulting from a high order brain processing in the spatial cognition network.

However in order to provide further insight into the mechanism underlying the postural effect of these sensory stimulation, we investigate the relation between shift of CP induced by the two stimulus types. Our hypothesis was that these stimulations could share a common central mechanism. Our findings show that the magnitude of the displacement induced by the Okn and Gv stimulations are linearly correlated. This linear effect reinforces the assumption that the postural effect of the sensory stimulation is a supramodal effect. Sensory stimulations could activate supramodal structures which synthesize information from disparate sensory modalities to create body's representation in space. This is consistent with previous neuroimagery findings. The effect of Okn stimulation is not due to a simple phenomenon confined to the visual modality, but is extended to the other areas such as proprioception and vestibular systems, as Okn stimulation activates not only visual areas, but also other cerebral areas, notably multisensory areas (Brandt et al 1998, Dieterich et al 2000). Similarly, the effect of Gv stimulation is not confined to the vestibular tracts, but also involves multisensory areas (Bense et al 2001, Guldin and Grusser 1998, Zink et al 1998). Thus, the postural effect 
of sensory stimulation probably results from activation of the supramodal areas that are situated at high level CNS centres, i.e the right posterior parietal cortex and the temporoparietal junction. This is also in accordance with the findings that show lesions of the right multisensory temporo-parietal junction have been found to be related to imbalance after stroke (Bonan et al 2004, Pérennou 2005). Moreover, distortions of spatial references (the subjective vertical or longitudinal axis), that are linked to the postural bias, are elaborated in such multisensory areas and are related to postural imbalance (Barra et al 2009, Bonan et al 2006, Bonan et al 2007, Pérennou et al 2008, Pérennou et al 2014). Finally, the results of several fMRI studies in stroke patients support the assumption for corrective action using Okn stimulation for spatial bias mostly via reactivation of the damaged right hemisphere spatial network situated on the posterior part of the parietal cortex (Boileau et al 2002, Thimm et al 2009, Zoccolotti et al 1992). Similar findings were reported by Fink et al (2003) for vestibular Gv stimulation.

In these supramodal areas, vestibular, auditory, neck proprioceptive and visual inputs are combined to create higher order spatial views of our body's position in relation to our environment. The body's representation in space is actually constructed in the right hemisphere with information coming from the peripheral sensory systems combined with movement signals and messages about planned actions (Grazziano 1994). Therefore, this process involves creating multiple representations of space using a process of modulation of various signals coded from different frames of reference (Andersen 1993). When a right focal brain lesion produces a disconnection in the circuits supporting one or more of these spatial encoding systems, a general imbalance of the spatial reference frame can occur (Karnath 1996, Pizzamiglio et al 1990, Vallar et al 1993). Activation of one or the other of these impaired systems by sensory input might be sufficient to partially compensate for the spatial 
bias which is manifested in a variety of spatial tasks, including posture. Sensory stimulation could act by modifying the alteration of the body representation and may not need to be simultaneously activated (Pizzamiglio et al 1990).

However, detailed analysis of individual patient data indicated that some patients responded to one or other type of sensory stimulation, but not to both. Some patients responded to Okn stimulation and not to Gv stimulation, while the reverse was also true. This little dissociation suggests there may be a partly functional independence between the Gv and Okn tracts. The central network stimulated by the 2 sensory inputs is likely to slightly differ even if it is situated in multisensory areas. How well a stimulation modality works may depend on the characteristics of the lesion. Therefore, it would be useful to identify those patients likely to respond to each type of stimulation before commencing treatment. This result is consistent with the findings of Karnath (1994) who found increased benefits when using visual and proprioceptive stimulation together. The reduction of bias that occurred when the 2 types of sensory stimulation were combined correlated with the sum of the respective bias correction when either type of stimulation was applied alone.

$\mathrm{Gv}$ is an appealing technique for rehabilitation treatment since it is safe, it can be easily administered and produces very few adverse effects, which contrasts with caloric-vestibular stimulation (Utz et al 2011). Okn is also easy to apply and is already used in numerous centres for vestibular symptoms. In this study, we observed that the corrective effect was 1.6 times higher with Okn than with Gv, however, the quantitative smaller beneficial effect of Gv compared to Okn is probably due to the intensity of the stimulation which was arbitrarily chosen and based on our previous studies. In these studies, we used Gv and Okn stimulation in a different context (Bonan et al 2013, Yelnik et al 2006) as we manipulated sensory information through multidirectional Okn and Gv stimulation in order to test the response of 
stroke patients to sensory information and to study sensory dependence (Bonan et al 2013, Yelnik et al 2006). Interestingly we observed that some patients were stabilised by Okn stimulation (Yelnik et al 2006) and that Okn or Gv lateral stimulation usually induced a corrective lateral displacement of the CP (Bonan et al 2013). Then, we chose a monodirectional stimulation, i.e. lateral, with a speed of rotation for Okn of 60 degrees per second which led to effective correction of the postural bias, and an intensity of $2 \mathrm{~mA}$ for $\mathrm{Gv}$ stimulation to avoid resultant unpleasant tingling.

In conclusion, postural asymmetry is reduced by sensory stimulation in RHL and LHL patients, however the postural effect was nearly double for LHL patients compared to that for RHL. Moreover, the magnitude of the displacement induced by the Okn and Gv stimulations are linearly correlated, suggesting a common or at least overlapping central mechanism of these two techniques in relation to postural control. Our results support a high level cortical postural effect of sensory stimulation in supramodal central nervous centres. It may be hypothesised that repetitive application of Okn and Gv might induce improvements which outlast the stimulation period. However, currently there are some studies where this approach has been tested on neglect symptoms. Repetitive Okn has been investigated (Kerkhoff et al 2001, Kerkhoff et al 2006), as well as repetitive Gv (Kerkhoff et al 2011, Sturm et al 2013, Thimm et al 2009). These investigators found stable treatment effects that outlasted the stimulation period resulted. Two recent randomized control group treatment studies of Oks provided clear evidence that repetitive Oks ameliorate lastingly multimodal (visual and auditory) neglect symptom in patients with right hemisphere lesion (Kerkhoff et al 2013, Kerkhoff et al 2014). Likewise, another recent study using repetitive Gv as treatment for RHL with left arm proprioceptive disorder could be temporarily normalised during and after a session of 20 min of Gv. (Schmidt et al 2013). Finally, 3 sessions of Gv were shown to 
reduce leftsided somatosensory extinction by some $50 \%$, the effects were lasting at least 3 months (Schmidt et al 2013). These studies underlines that Oks and Gv (the two techniques used in the present manuscript) are likely to unfold also significant and permanent treatment effects on postural capacities in patients with stroke, probably most in right-sided stroke, when applied repetitively as a treatment. Further studies are needed to investigate the therapeutic potential of repetitive Gv or Okn stimulation to achieve longer lasting improvements in postural disturbances. The combined effect of sensory stimulation should also be tested since the effects appear to be cumulative (Karnath et al 1994). 


\section{CONFLICT OF INTEREST}

None of the authors have potential conflicts of interest to disclose. 


\section{REFERENCES}

Andersen RA, Snyder LH, Li CS, Stricanne B. Coordinate transformations in the representation of spatial information. Curr Opin Neurobiol 1993;3:171-176.

Barra J, Oujamaa L, Chauvineau V, Rougier P, Pérennou D. Asymmetric standing posture after stroke is related to a biased egocentric coordinate system. Neurol 2009;72(18):15821587

Bense S, Stephan T, Yousry TA, Brandt T, Dieterich M. Multisensory cortical signal increases and decreases during vestibular galvanic stimulation (fMRI). J Neurophysiol $2001 ; 85: 886-899$

Berg K, Wood-Dauphinee S, Williams JI, Gayton D. Measuring balance in the elderly: preliminary development of an instrument. Physiother Can 1989;41:304-311

Boileau I, Beauregar M, Beuter A, Breault C, Lecours AR. Optokinetic stimulation and the egocentred midsagittal plane: an fMRI study. Neuroreport 2002;13(1):61-65

Bonan IV, Colle FM, Guichard JP, Vicaut E, Eisenfisz M, Tran Ba Huy P, Yelnik AP. Reliance on visual information after stroke. Part I: Balance on dynamic posturography. Arch Phys Med Rehabil 2004;85(2):268-273

Bonan IV, Guettard E, Leman MC, Colle FM, Yelnik AP. Subjective visual vertical perception relates to balance in acute stroke. Arch Phys Med Rehabil 2006;87(5):642-646 Bonan IV, Hubeaux K, Gellez-Leman MC, Guichard JP, Vicaut E, Yelnik AP. Influence of subjective visual vertical misperception on balance recovery after stroke. J Neurol Neurosurg Psychiatr 2007;78(1):49-55 
Bonan IV, Marquer A, Eskiizmirliler S, Yelnik AP, Vidal PP. Sensory reweighting in controls and stroke patients. Clin Neurophysiol 2013;124:713-722

Brandt T, Bartenstein P, Janek A, Dieterich M. Reciprocal inhibitory visual-vestibular interaction. Visual motion stimulation deactivates the parieto-insular vestibular cortex. Brain $1998 ; 121: 1749-1758$

Collin C, Wade D. Assessing motor impairment after stroke: a pilot reliability study. J Neurol Neurosurg Psychiatr 1990;53:576-579

Dieterich M, Brandt T. Brain activation studies on visual-vestibular and ocular motor interaction. Curr Opin Neurol 2000;13:13-18

Fink GR, Marshall JC, Weiss PH, Stephan T, Grefkes C, Shah NJ, Zilles K, Dieterich M. Performing allocentric visuospatial judgments with induced distortion of the egocentric reference frame: an fMRI study with clinical implications. Neuroimage 2003;20(3):15051517

Genthon N, Rougier P, Gissot AS, Froger J, Pélissier J, Pérennou D. Contribution of each lower limb to upright standing in stroke patients. Stroke 2008;39(6):1793-1799

Graziano M, Gross C The representation of extrapersonal space: a possible role for bimodal visual-tactile neurons. In The cognitive neurosciences (eds M Gazzaniga 1994), 1021-34 MIT Press, Boston

Guldin WO, Grusser OJ. Is there a vestibular cortex? Trends Neurosci 1998;21: 254-259

Karnath HO. Subjective body orientation in neglect and the interactive contribution of neck muscle proprioception and vestibular stimulation. Brain 1994;117:1001-1112 
Karnath HO.Optokinetic stimulation influences the disturbed perception of body orientation in spatial neglect. J Neurol Neurosurg Psychiatr 1996;60(2):217-220

Kerkhoff G. Spatial hemineglect in humans. Prog Neurobiol 2001;63(1):1-27

Kerkhoff G, Keller I, Ritter V, Marquardt C. Repetitive optokinetic stimulation induces lasting recovery from visual neglect. Restor Neurol Neurosci 2006;24(4-6):357-369

Kerkhoff G, Keller I, Artinger F, Hildebrandt H, Marquardt C, Reinhart S, Ziegler W. Recovery from auditory and visual neglect after optokinetic stimulation with pursuit eye movements-transient modulation and enduring treatment effects. Neuropsychologia 2012;50(6):1164-1177

Kerkhoff G, Bucher L, Brasse M, Leonhart E, Holzgraefe M, Völzke V, Keller I, Reinhart S. Smooth Pursuit "Bedside" Training Reduces Disability and Unawareness During the Activities of Daily Living in Neglect: A Randomized Controlled Trial. Neurorehabil Neural Repair. 2014;28(6):554-563.

Kerkhoff G, Reinhart S, Ziegler W, Artinger F, Marquardt C, Keller I. Smooth pursuit eye movement training promotes recovery from auditory and visual neglect: a randomized controlled study.Neurorehabil Neural Repair. 2013 Nov-Dec;27(9):789-98Mahoney FI, Barthel DW. Functional evaluation: the Barthel Index. Md State Med J 1965;14:61-65

Pérennou DA, Amblard B, Laassel el-M, Pélissier J. Hemispheric asymmetry in the visual contribution to postural control in healthy adults. Neuroreport 1997;8(14):3137-3141

Pérennou DA, Amblard B, Leblond C, Pélissier J. Biased postural vertical in humans with hemispheric cerebral lesions. Neurosci Lett. 1998;14;252:75-78 
Pérennou DA, Leblond C, Amblard B, Micallef JP, Hérisson C, Pélissier JY. Transcutaneous electric nerve stimulation reduces neglect-related postural instability after stroke. Arch Phys Med Rehabil 2001;82(4):440-448

Pérennou D. Weight bearing asymmetry in standing hemiparetic patients. J Neurol Neurosurg Psychiatr 2005;76(5):621

Pérennou DA, Mazibrada G, Chauvineau V, Greenwood R, Rothwell J, Gresty MA, Bronstein AM. Lateropulsion, pushing and verticality perception in hemisphere stroke: a causal relationship? Brain 2008;131:2401-2413

Pérennou D, Piscicelli C, Barbieri G, Jaeger M, Marquer A, Barra J. Measuring verticality perception after stroke: why and how? Neurophysiol Clin 2014;44(1):25-32

Pizzamiglio L, Frasca R, Guariglia C, Incoccia C, Antonucci G. Effect of optokinetic stimulation in patients with visual neglect. Cortex 1990;26(4):535-540

Podsiadlo D, Richardson S. The Timed Up and Go: a test of basic functional mobility for frail elderly persons. J Am Geriatr Soc 1991;39:142-148

Rode G, Tiliket C, Boisson D. Predominance of postural imbalance in left hemiparetic patients. Scand J Rehabil Med 1997;29(1):11-16

Rode G, Tiliket C, Charlopain P, Boisson D. Postural asymmetry reduction by vestibular caloric stimulation in left hemiparetic patients. Scand J Rehabil Med 1998;30(1):9-14

Roerdink M, Geurts AC, de Haart M, Beek PJ. On the relative contribution of the paretic leg to the control of posture after stroke. Neurorehabil Neural Repair 2009;23(3):267-274 
Schmidt L, Keller I, Utz KS, Artinger F, Stumpf O, Kerkhoff G. Galvanic vestibular stimulation improves arm position sense in spatial neglect: a sham-stimulation-controlled study. Neurorehabil Neural Repair. 2013;27(6):497-506

Schmidt L, Utz KS, Depper L, Adams M, Schaadt AK, Reinhart S, Kerkhoff G. Now You Feel both: Galvanic Vestibular Stimulation Induces Lasting Improvements in the Rehabilitation of Chronic Tactile Extinction. Front Hum Neurosci. 2013;7:90

Sturm W, Thimm M, Binkofski F, Horoufchin H, Fink GR, Küst J, Karbe H, Willmes K. Combined space and alertness related therapy of visual hemineglect: effect of therapy frequency. Front Hum Neurosci 2013;7:373

Talairach J, Tournoux P. Coplanar stereotaxic atlas of the human brain: 3 dimensional proportional system: an approach to cerebral imaging. Stuttgart: Thieme, 1988

Thimm M, Fink GR, Küst J, Karbe H, Willmes K, Sturm W. Recovery from hemineglect: differential neurobiological effects of optokinetic stimulation and alertness training. Cortex. $2009 ; 45(7): 850-862$

Tilikete C, Rode G, Rossetti Y, Pichon J, Li L, Boisson D. Prism adaptation to rightward optical deviation improves postural imbalance in left-hemiparetic patients. Curr Biol 2001;11(7):524-528

Utz KS, Korluss K, Schmidt L, Rosenthal A, Oppenländer K, Keller I, Kerkhoff G. Minor adverse effects of galvanic vestibular stimulation in persons with stroke and healthy individuals. Brain Inj. 2011;25(11):1058-69 
Vallar G, Antonucci G, Guariglia C, Pizzamiglio L. Deficits of position sense, unilateral neglect and optokinetic stimulation. Neuropsychologia 1993;31(11):1191-1200

Yelnik AP, Lebreton FO, Bonan IV, Colle FM, Meurin FA, Guichard JP, Vicaut E.

Perception of verticality after recent cerebral hemispheric stroke. Stroke 2002;33(9):22472253

Yelnik AP, Kassouha A, Bonan IV, Leman MC, Jacq C, Vicaut E, Colle FM. Postural visual dependence after recent stroke: assessment by optokinetic stimulation. Gait Posture 2006;24(3):262-269

Zink R, Bucher SF, Weiss A, Brandt T, Dieterich M. Effects of galvanic vestibular stimulation on otolithic and semicircular canal eye movements and perceived vertical. Electroencephalogr Clin Neurophysiol 1998;107:200-205

Zoccolotti P, Guariglia C, Pizzamiglio L, Judica A, Razzano C, Pantano P. Good recovery in visual scanning in a patient with persistent anosognosia. Int J Neurosci 1992;63(1-2):93-104 


\section{TABLES}

Table 1. Demographic Data LHL and RHL Patients (Mean and SD).

\begin{tabular}{|lllll|}
\hline & Total & RHL & LHL & p-value \\
Age (y) & $54.1(10.6)$ & $56.8(9.7)$ & $51.6(11.1)$ & 0.133 \\
Delay since stroke & $3.0(1.3)$ & $3.2(1.5)$ & $2.8(1.2)$ & 0.309 \\
(months) & & & & \\
Barthel index (/100) & $88.5(13.9)$ & $87.5(12.2)$ & $89.4(15.5)$ & 0.262 \\
Motor index (/100) & $61.9(20.4)$ & $63.4(19.8)$ & $60.5(21.4)$ & 0.843 \\
Timed up and go (sec) & $26.8(26.7)$ & $29.5(32.5)$ & $24.5(21.6)$ & 0.704 \\
10 m (sec) & $18.8(16.6)$ & $18.3(14.2)$ & $19.3(18.9)$ & 0.945 \\
BBS (/56) & & & & \\
X0 (mm) & $48.9(7.2)$ & $47.8(8.4)$ & $49.8(6.0)$ & 0.569 \\
\hline & $21.8(24.4)$ & $30.2(29.9)$ & $13.8(14.7)$ & 0.0477 \\
\hline & & & & \\
\hline
\end{tabular}

$\mathrm{XO}$ is the mean position on the mediolateral axis during the 50s-rest recording 
Table 2. Effect of Sensory Stimulation towards Right and Left Direction (Okn and Gv Stimulation). Displacement during Stimulation Expressed in Absolute Values.

\begin{tabular}{|lccc|}
\hline & Control & LHL & RHL \\
R-Okn & $10.9(\mathrm{SD} 17.6)$ & $9.7(13.7)$ & $9.3(16.5)$ \\
L-Okn & $9.4(15.6)$ & $10.4(16.0)$ & $25.8(23.8)$ \\
R-Gv & $3.6(7.8)$ & $8.3(10.8)$ & $9.3(11.7)$ \\
\hline & $7.4(10.1)$ & $4.2(8.8)$ & $14.2(17.1)$ \\
\hline
\end{tabular}

Key:

R-Okn: lateral displacement of the subjects under the Okn stimulation toward the right

L-Okn: lateral displacement of the subjects under the Okn stimulation toward the left

R-Gv: lateral displacement of the subjects under the Gv stimulation toward the right

L-Gv: lateral displacement of the subjects under the Gv stimulation toward the left

LHL: patients with left hemispheric lesion

RHL: patients with right hemispheric lesion 
Figure 1: Displacements of the subjects during galvanic (Gv) and optokinetic (Okn) stimulations (above: Okn stimulation, below: Gv stimulation) among the 3 groups of patients (LHL: red, RHL: blue, Controls: green): CP position during stimulation was displaced either left (negative values) or right (positive values) according to the direction of the stimulation in all 3 groups. There was a significant group effect $(F=7.52, p<0.001)$, together with a significant group $\mathrm{x}$ direction interaction $(\mathrm{p}=0.007)$ showing that displacement was higher with respect to left stimulation only in RHL patients, compared with controls and LHL patients and right displacement did not differ between the 3 groups $(p=0.668)$. RHL right hemisphere lesion, LHL left hemisphere lesion.

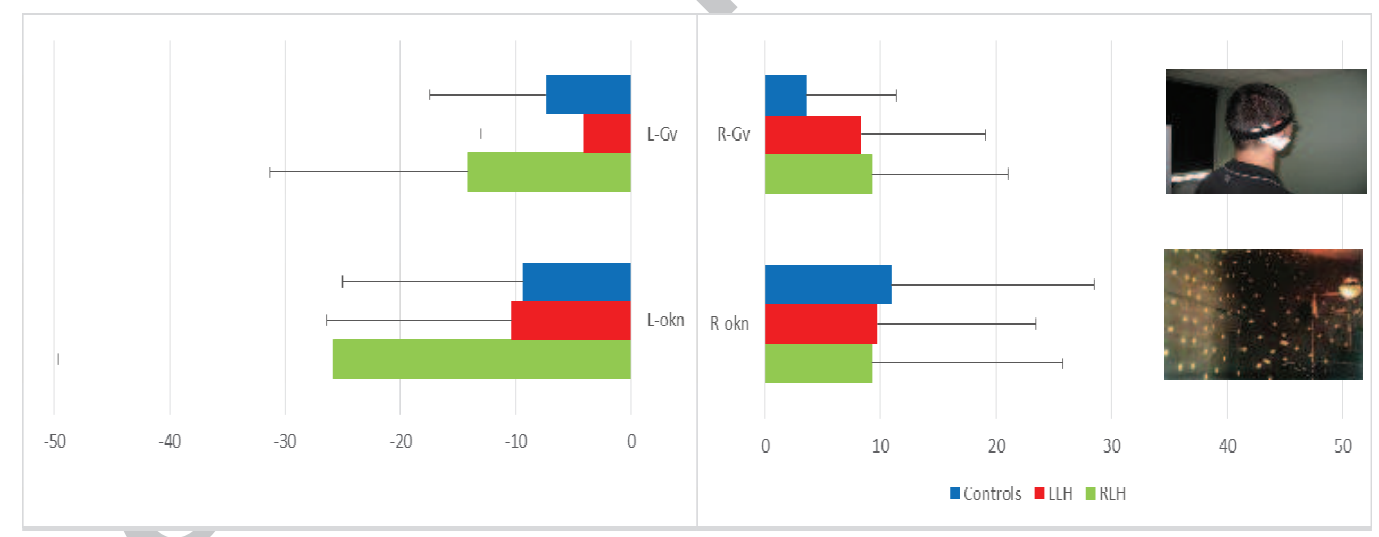


Figure 2: Relationship between the Displacement Under Okn Stimulation and the

Displacement Under Gv Stimulation Among the 3 Groups Of Patients: The magnitude of displacement was positively correlated between Okn and Gy (rho=0.635, p<0.001).

Each point represents the Gv and Okn responses to the left or to the right oriented stimulus (+ lateral displacement toward the right and - lateral displacement toward the left).

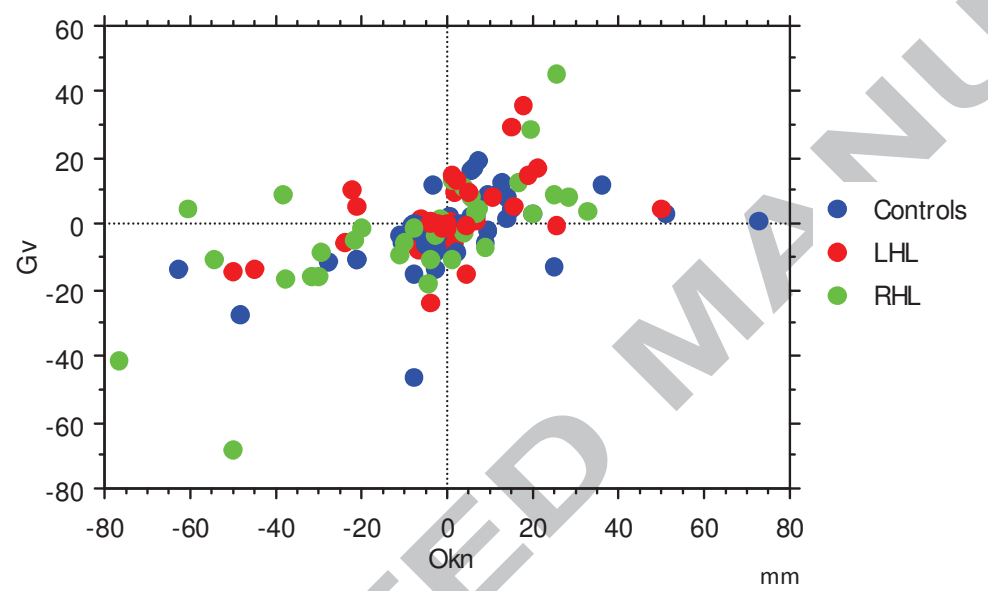

